\title{
Responsabilidade do Jurista Brasileiro Perante a Nação*.
}

\author{
Irineu Strenger \\ Professor Titular de Direito Internacional Privado na \\ Faculdade de Direito da Universidade de São Paulo
}

Como palavras iniciais destacamos o profundo orgulho que esta oportunidade desperta em nosso ser pleno. Falar neste auditório é sempre uma sensação especial. Quando fomos informados de que abriríamos os cursos jurídicos deste ano letivo, com a significação singular de estarmos comemorando o sesquicentenário de fundação desta Escola, compreendemos a força da tradição e sentimos no íntimo a grave tarefa que nos impunha a desincumbência do honroso dever funcional.

Nesses momentos procelosos a mente se eletriza, move-se a imaginação, vibram-se todas as cordas do peito na escolha do tema. Algo que fosse oportuno e compatível com a grandeza das Arcadas. Algo que não ficasse apenas no registro dos atos convencionais. Algo que pudesse representar a expressão da História que esta Escola em grande escala ajudou a construir. Deparamo-nos com nossas próprias limitações no cumprimento do encargo, mas, de súbito sentimos a imposição existencial de abordar assunto que colocasse novamente em foco o papel do jurista no processo histórico e político do Brasil, embora no seu contexto genérico já tivesse sido examinado sob inúmeras perspectivas. O problema continua, porém, candente na ordem do dia e sua inesgotabilidade está em função da riqueza do conteúdo e na sua estrutura dialética.

Fa-lo-emos, contudo, despretenciosamente, com fidelidade ao espiríto deste Templo do saber jurídico. Recebam, pois, nossas palavras como o diálogo da intimidade exteriorizada, como pronunciamento concatenado em frases espontâneas oriundas de nossa experiência de professor, de advogado e de

* Aula Inaugural dos Cursos Jurídicos da Faculdade de Direito da Universidade de São Paulo proferida no Salão Nobre, aos 9 de março do corrente ano. 
homem comum, num momento em que o silêncio deve ser rompido, para que cada qual preste seu testemunho e permita a instauração do processo de intersubjetividade concreta, alimentando aquele que não vê e não sente, "a preexistência de ver, ouvir e palpar o que os olhos não divisam, os ouvidos não escutam e o tato não percebe".

Em 1872 um dos mais preeminentes jurisconsultos do mundo e sublime pensador, R. VON JHERING, divulgava precioso opúsculo denominado $A$ luta pelo direito no qual proclamava enfaticamente e ainda com muita atualidade: "A paz é o objetivo que o direito visa, mas, a luta é o meio de atingi-la. Ao mesmo tempo em que o direito deve contar com os ataques da injustiça", - e isto existirá enquanto o mundo existir ele não estará livre da luta. A vida do Direito é uma luta: luta dos povos, do Estado, de classes, dos indivíduos. Todos os direitos do mundo foram alcançados na luta; todas as regras importantes do direito tiveram que começar por ser arrebatadas daqueles que se lhe opunham, e todo direito, direito de um povo ou de um indivíduo pressupõe que se esteja constantemente preparado a sustentá-lo. $O$ direito não é pura teoria, mas, força viva. A Justiça também, traz numa das mãos a balança com a qual pesa o Direito, na outra a espada com a qual o defende. A espada sem a balança é a força bruta, a balança sem a espada é a impotência do Direito. Uma não pode caminhar sem a outra, e não existe ordem jurídica perfeita, senão onde a energia com que a Justiça porta a espada é igual à habilidade com que maneja a balança. O Direito é trabalho incessante não somente do Poder Público, mas de todo o povo. A vida do Direito considerada em seu conjunto, representa o próprio espetáculo da luta e do trabalho sem tréguas de toda uma nação, que oferece a atividade dos povos no domínio da produção econômica e intelectual."

$O$ pensamento de IHERING traduz de modo expressivo que a luta pelo direito é um dever do interessado em relação a si mesmo, e, pois, a defesa do direito um dever da conservação moral de cada homem. O Estado que deseja ser estimado exteriormente, sendo sólido e inquebrantável interiormente, não possui bem mais precioso a cultivar para a Nação do que o sentimento do Direito.

Vivemos, porém, uma época angustiante. Sentimos que o Direito se incapacita no seu desiderato intrínseco de empunhar a espada para defender suas prerrogativas, porque a maioria dos seus "soldados", os juristas, entregou-se à perigosa 
passividade da não participação, deixando o terreno livre para os profissionais do "antidireito", que aceitam, e se desencumbem das encomendas, para vestir monstrengos de roupagem jurídica.

Nosso pronunciamento desta tribuna sagrada não é uma proclamação estigmatizada pela política, mas um clamor pelo despertar da consciência jurídica nacional, na luta pelo Direito, de modo que cada jurista pátrio não atravesse incólume o granizo de abusos, a que os vizinhos vão sucumbindo, entregues a reprovável conformismo, podendo levar a breca o nosso próximo às mãos de todos os despostismos, uma vez que por casa nos vá tudo bem. "O egoismo é um para-raio que nunca preservou ninguém; mas, os egoistas são fanáticos por ele."

Pode, porém, o egoismo conciliar-se com a virtude? Se cada um seguir apenas seu interesse, redundará disso algo util para a coletividade, para "o bem comum"?

Respondemos acompanhando ROQUE SPENCER MACIEL DE BARRoS em sua obra consagrada, Introdução à filosofia liberal, quando assinala que "é a partir da liberdade, da autoconsciência e da responsabilidade que o homem constrói a civilização, elabora a ciência e se transforma numa pessoa, dando a si próprio leis éticas que podem valer universalmente. Mas, a liberdade pesa-lhe, a responsabilidade é sempre um fardo doloroso: elas são "antinaturais", na medida que a cultura, que nelas se funda, se é um prolongamento da natureza, é também uma oposição em face da "naturalidade" pura. E, com freqüência, o homem se deixa dominar pelo terror cósmico, pelo pavor de ser ele mesmo e mais ninguém, de ser insubstituível e único, pelo temor de decidir livremente e de ser responsável pelas suas decisões. $\mathrm{E}$ então se lhe oferece o caminho da desumanização, o desejo de perder-se na primitiva totalidade indiferenciada, de desvencilhar-se da consciência e da decisão, de retornar à mera animalidade ou de converter-se num robot, mecanicamente guiado e liberto da dor de pensar, do sofrimento da escolha. Renasce o mito do paraíso perdido ou elabora-se o mito do fim paradisíaco da história, paraísos em que já não há limitação, já não há necessidade de escolha e no qual não pode haver mais liberdade, não pode haver a singularidade, o "único", que é a característica própria do homem, trágico, mas plenamente humano. $\mathrm{E}$ desse terror da própria individualidade, do medo de decidir, alimenta-se o totalitarismo." 
"Ele promete ao homem o fim da consciência, a desnecessidade do pensamento, a libertação do "terror metafísico" próprio da condição humana, ainda que seja pelo exercício do terror policial coletivo. Promete ao homem reduzi-lo a uma mera parte do todo indiferenciado, oferece-lhe o ópio da despersonalização. Promete-lhe converter o poder em algo total e absoluto, eliminar as limitações e as oposições e instituir o reino da totalidade. Promete-lhe o êxtase místico, a comunhão com o deus visível e encarnado na figura do "chefe". Ensina-lhe a "religião do Estado", a submissão completa que o liberará finalmente de sua trágica humanidade."

"Eis ai, - complementa ROQUe SPENCER - a raiz profunda do totalitarismo, a força de seu apelo. Ele conquista os homens quando estes temem a condição humana, quando não conseguem mais ser homens, quando se apavoram diante da própria liberdade. Por esse motivo o combate ao totalitárismo nunca se acaba. Porque não se trata apenas de combater este ou aquele inimigo, visível, encarnado ora no fascismo, ora no comunismo. Trata-se, também, de combater o inimigo que trazemos dentro de nós próprios, o animal temeroso das decisões que se esconde nas profundezas de nossa alma. E é a constância desse combate que garante a sobrevivência de nossa verdadeira humanidade. Por isso, não pode haver trégua. Dentro de nós ou encarnado no outro, principalmente quando o outro representa o Poder, é preciso sempre opor ao "nihilismo totalitário" a lucidez da consciência livre, apostando na condição humana com sua grandeza e miséria, suas incertezas e limitações. $E$ porque não pode haver trégua é necessário denunciar sempre o apelo ao totalitarismo, seja qual for sua forma. Na sua significação mais profunda, todos os totalitarismos se equivalem, todos não fazem senão um: opostos na aparência, move-os o mesmo desejo de apagar a consciência, de suprimir a liberdade, de eliminar a individualidade. E o homem que apostou na condição humana não poderá ser enganado pelo totalitarismo que, para conquistá-lo, procure convencê-lo de que todo o mal se acha apenas em uma forma totalitária qualquer. Porque esta é apenas uma das cabeças da mesma hidra devoradora do homem concreto, trágico e singular, livre e humano"

A responsabilidade do jurista brasileiro perante a nação genericamente repousa no dever precípuo de sair, objetivamente do estado de ambigüidade, de não submeter suas idéias ao juízo dos outros, de não deixar envolver-se pelo antiintelectualismo manifestado na linguagem artificiosa e sedutora de 
palavras sem conteúdo (com efeito, a palavra meramente adaptada à vida, à existência empírica, não pode expressar a verdade do homem, que é sua relação concreta e dinâmica com a sociedade), de não conceder ao irracional o que for preciso para impor sua autoridade, não substituir as relações rigorosas, necessárias, que a ciência estabelece, por relações tênues e contestáveis.

Há, sem dúvida, uma certa patologia jurídica preponderando. Há, sem dúvida, uma certa insensibilidade jurídica à dor causada pela violação do direito. Tal atitude existencial pode levar à perda da excitabilidade do sentimento jurídico, o qual aumenta ou diminui na medida em que um indivíduo, uma classe, um povo considere o direito ou instituição de direito como condição moral de sua existência.

A justificação para atribuir responsabilidade é, portanto, o efeito presumido derivado dessa prática, nas ações futuras. Se atribuimos aos homens liberdade porque presumimos que são seres racionais, dita liberdade deve valer a pena na hora de agir, como tais seres racionais e permitir-lhes suportar as consequiências de suas decisões. É licito admitir que os juristas têm qualidades e conceito para se tornarem "fiéis depositários" dessa responsabilidade, pois, mais do que ninguém, os juristas experimentam as normas sociais introjetadas como sua própria consciência. E, por outro lado, não somente são um espelho da coerção e autoridade externa, como também, uma projeção de sua própria personalidade. A consciência jurídica não é simples adaptação individual, mas, também a sua própria auto-realização. A consciência de nossa própria ação constitui esse complexo de vivências que se expressa nas mais variadas objetivações. E a compreensão das formas de atuação das outras consciências repousa evidentemente num acervo de experiências próprias e pessoais. A nossa liberdade evolui entre os produtos da liberdade do outro e na ação encontramo-nos sempre envoltos num mundo de objetividades e utensílios criados pelas outras existências.

Colocar de repente o jurista em face da sociedade, pode revelar, como lembra ANDRÉ JEAN ARNAUD, duas atitudes: o culto do paradoxo ou a exposição brutal de uma contradição, pois, não é fato que a própria existência da sociedade determina a função do jurista? Contudo esse face a face entre os juristas e a sociedade constitui "o pensamento jurídico" e, exatamente, desse pensamento jurídico é que devemos falar 
para determinar-lhe o objeto diante da realidade brasileira atual.

Sem entrar no campo das explicações minuciosas, possivelmente ninguém replicará que, panoramicamente, do ponto de vista sócio-econômico e político, a conjuntura brasileira se caracteriza por três espécies de fatos: a gravidade da crise econômica, intervenção crescente do Estado e instabilidade política, nos planos nacional e internacional.

A situação tal qual genericamente descrita obriga a repensar o Direito em função de sua essencialidade. Em outras palavras: a tríade que acabamos de mencionar, concentra toda problemática nacional e a sua decomposição analítica é tarefa dos especialistas. Contudo não pode escapar ao jurista a visão global do fenômeno cuja explicação se fecunda na determinação da legitimidade das fontes emanadoras do direito.

Legitimidade, assim como legalidade, são atributos do Poder. Na linguagem dos juristas essas categorias são usualmente empregadas como sinônimas, ambas indicando conformidade com as leis estabelecidas. Contudo parece grave equívoco não considerar duas condições, para que se possa dizer que uma ação é conforme às leis estabelecidas: $10^{\circ}$ ) o sujeito tem o direito de fazer; $2^{\circ}$ ) o sujeito, que tem o direito de fazer, o faz dentro dos limites preestabelecidos. Isto significa que existem sempre duas vias diferentes, pelas quais se pode contestar a conformidade de uma ação às leis estabelecidas: ou se demonstra que o sujeito agiu não tendo o direito de agir; ou bem o sujeito tinha o direito de agir, mas não respeitou as regras prescritas para essa ação.

O poder é força, porém não cega, mas orientada racionalmente para a consecução de um fim. Esse fim deve ser exterior a ele, no sentido de que constitua um objetivo a cujo serviço se coloca o poder. Mas, pode ocorrer, também, que o poder pelo poder se converta em fim. Então estaremos diante do claro impulso de dominação, diante da pura vontade de poder, ou afirmação de si mesmo, sobre os outros. Esta substantivação do poder não se dá de forma necessariamente cega; pelo contrário, realiza-se muitas vezes sob a forma de um voluntarismo que se utiliza da inteligência para seu crescimento. Por isso pode falar-se do caráter demônico do poder, no sentido grego, quer dizer ambígüo e moralmente ambivalente. De demônico a demoníaco não há semanticamente muita separação. Por isso, freqüentemente ao longo da história, se tem considerado o poder como um mal, como uma tentação pelo 
menos e, às vezes como um pecado. Pecado necessário e que, por isso mesmo, deve ser reduzido a um mínimo, mediante a limitação do poder. Recorde-se a tão conhecida frase de Lord ACTON: "O poder corrompe; o poder absoluto corrompe absolutamente". Outro escritor WERNER BERGENGRÜN escreveu: "A grande contradição do mundo: as mãos limpas são fortes; as fortes não podem permanecer limpas". O poder como força desnuda, isto é, no plano político a utilização de meios policialescos, de violência física, de constrangimento, se multiplica com o uso da inteligência. Uma característica moderna dessa ampliação do poder é a sua tecnicização que, além de fortalecê-lo, o converte em aparato produtor da sensação de onipotência e irresistibilidade, de poder sem limites. o terror como criação de um suspense coletivo, de uma ameaça sempre erguida sobre a cabeça do cidadão, da qual não se pode absolutamente fugir. Esse aspecto do poder nos regimes totalitários modernos é muito favorecedor da sua mitificação - uma mitificação de novo estilo, que gera, inclusive a mistificação, pois, a desordem, a arbitrariedade, a corrupção, a rotina, a incompetência podem ser encobertas pelo mistério metafísico.

Tenha-se tal configuração descritiva para ser dialeticamente meditada, e chegaremos a sombrias conclusões prospectivas.

Que não se defendam, porém, os que lideram o antimovimento de reconstrução democrática deste país, imputando-nos e aos que lhe são adversos, a responsabilidade do comprometimento com outras facções ou a pecha de saudosistas. Nada disso. Tornamo-nos apenas desesperançosos, desconfiantes do regime. Reconhecemos que a Revolução de 64 foi um imperativo do momento histórico, mas, não podemos negar que sua evolução conflita com os propósitos originários levando-nos a ser absorvidos no perigoso processo do entorpecimento, resultante da não participação.

Convenhamos que o político brasileiro é habil artífice de modelos e os exemplos proliferam.

Como diz em primorosas linhas RAFaEL VALENTINo SoBRINHo, ex-brilhante aluno desta Casa, atualmente secretário de Embaixada, em exercício na Embaixada do Brasil em Londres, no seu trabalho $A$ função político-econômica $d a$ ignorância no Direito Constitucional Brasileiro contemporâneo - "os cientistas políticos e constitucionalistas encarapitaram-se no topo da "pirâmide profissional" de GalBRAITH, descrito 
como opaco e sem contato com a realidade, reservando-se a base ao "tecnocrata do cotidiano", transparente e com ação sobre a realidade. A imagem talvez tenha encontrado ressonância na decisão de um professor francês que abandonou sua cátedra de Direito Constitucional, por ter descoberto enfim a sua vocação. ensinar mitologia. Acontece, entretanto, que o mito, para ser eficaz deve ser em parte verdadeiro.

A proficiente análise de RAFaEL VALENTiNo prossegue: "Uma das características na Constituição Brasileira vigente é a consciência dos impasses inerentes à vida política contemporânea, notadamente o que se configura entre a tecnocracia no Poder Executivo e a vontade difusa de participação política da faixa extratecnocrática, cujo veículo de expressão deve ser o Legislativo."

"O otimismo brasileiro, tão decantado na sua visão superficilista, está enfrentando o seu momento de verdade. 0 modelo em vigor tem uma abertura para o "otimismo epistemológico" que é o caminho para as idéias do liberalismo, como aponta POPPER, partindo da premissa "o homem pode conhecer, portanto pode ser livre".

"A abertura para o otimismo não exclui a postulação, inevitável numa sociedade aberta, de um "racionalismo crítico", como o denomina o mesmo PoPPER. Para alcançar-se o equilíbrio dinâmico, que é caracterizado por esse racionalismo crítico, é essencial reformular as indagações distorcidamente cristalizadas da teoria política tradicional. Ao invés de indagar quem deveria governar, pergunta que demanda respostas autoritárias, tais como "os melhores", ou "os mais sábios", ou "o povo", ou "a maioria", ou até mesmo fórmulas comicamente bastardas de hibridização, como "consenso majoritário", "passividade ativamente consensual", é urgente substituir esses estereótipos por uma questão completamente diversa: "Como poderemos organizar nossas instituições políticas de maneira que os governantes maus ou incompetentes (que se procurará afastar, o que nem sempre é fácil) não possam causar danos? As indagações distorcidas que acima se exemplificam são análogas à pergunta acerca da fonte suprema do conhecimento e o seu debate em torno de um tolo dualismo: inteligência ou sentidos. A indagação correta, em matéria de fontes do conhecimento político, como do conhecimento em geral, é sintetizada por POPPER: "Como poderemos detectar e eliminar o erro?". 
"A resposta à indagação assim corretamente reformulada pode exaurir-se num autoritarismo tradicionalista sob 0 disfarce de roupagem modernizante, agravando-se assim consideravelmente a força repressiva do poder e a contra-explosividade latente na sociedade civil".

"Nesse particular, a preocupação histórica de retorno à democracia que inspirou a Constituição Brasileira vigente, deve ser preservada nos seus propósitos e na sua dinâmica. A história política do Brasil, na última década, deixa claro que três diretrizes básicas, na questão que ora se analisa, foram as constantes estruturais do pensamento político que se procurou traduzir na Constituição de 67: a proscrição do continuismo personalista, a partilha da responsabilidade política decisória durante o período de transição, para a descompressão política plena, e a concepção gradualista de uma descompressão dirigida. A partilha da responsabilidade política deu ao sistema consagrado na Constituição de 1967 e na Emenda n. ${ }^{\circ} 1$ especificidade até certo ponto original e democraticamente criadora, se a sua dinâmica não fosse impossibilitada pela inércia da imaginação social que deveria mobilizá-la".

$O$ valor instrumental de um sistema de governo, seu bom funcionamento, é uma necessidade objetiva, estimulada hoje pela aceleração da história, e uma exigência psicológica das novas gerações de mentalidade tecnicista e não retórica. Mas a eficácia, que em nosso tempo diz respeito primeiramente ao desenvolvimento econômico, não deve ser confundida com o decisionismo, tantas vezes disparatado e pelo menos medíocre, de alguns regimes para os quais o objetivo fundamental é a manutenção do autocrata no poder, ou da autocracia do poder.

A democracia não é, portanto, um status no qual o povo possa comodamente se instalar. E conquista ético-política de cada dia, que só através de uma autocrítica sempre vigilante pode ser mantida. É mais uma aspiração do que uma possessão. É como dizia KANT, referindo-se à moral em geral, uma tarefa infinita, na qual, se não se progride, se retrocede; isto porque inclusive o que já foi ganho há que reconquistar-se cada dia. $\mathrm{E}$, justamente por isso, a crítica feita fora da democracia, com a intenção de mostrar tristemente, facilmente - ou então cinicamente como também ocorre - que todos somos iguais (iguais no opróbio de submissão a poderes absolutos), ou que tudo vai bem destrói-se a si mesma, uma vez que a democracia, nunca pode deixar de ser luta pela democracia. 
$\mathrm{Na}$ verdade em momento algum o desempenho dos juristas foi tão importante, como na presente conjuntura nacional porque vivemos num estado crescente de coação, de perda da liberdade e independência enquadrados numa estrutura racionalista, e artificializante sob o influxo dos lemas e meios de propaganda, sugestionados pelos "slogans". Nossa ação se realiza sob coação que suprime e afoga a iniciativa pessoal, daí resultando a perda da responsabilidade do indivíduo. E somente se pode falar em responsabilidade no homem quando este atua com iniciativas próprias sob o impulso do próprio juízo e da própria determinação. Os lugares comuns são a trama ideológica fundamental, insidiosamente infiltrados em nossa consciência pelo movimento de fato e não de direito das máquinas governamentais. A palavra e a linguagem se impregnam de elementos mágicos, autoritários, rituais. 0 discurso está privado de termos mediatos que são as etapas do processo do conhecimento e de valoração cognoscitiva. Os conceitos que apreendem os fatos e que transcendem estão em vias de perder sua representação lingüística autêntica. A palavra se converte em clichê e a linguagem ao tornar-se funcional provoca uma redução do sentido que tem um conteúdo político. O substantivo governa a frase de um modo autoritário e absoluto e a frase se converte numa afirmação que deve ser aceita. Seu sentido declara, codifica, não pode ser demonstrado, modificado e negado. Daí a forma proposicional do discurso político que se justifica por si mesma. Nesse universo do discurso público, a palavra é um deslocamento de sinônimos e tautologias, sem procurar jamais a diferença qualitativa. A estrutura analítica isola a palavra principal daquelas, em seus próprios conteúdos, que implicariam em risco de invalidar, ou ao menos entorpecer o uso corrente da palavra empregada para declarações políticas e a opinião pública. O conceito ritualizado é imunizado contra a contradição. A contradição que outrora era a pior inimiga da lógica, é atualmente um princípio da lógica do condicionamento.

O homem médio atual (desculpem-nos o lugar comum), inserido no contexto brasileiro, aceita a nivelação de sua vida com a dos demais, a pré-fabricação de sua mente por poderes anônimos, qualquer gênero de coação, na mesma medida em que experimenta um desapego básico, uma rebelião crescente contra o mundo e a sociedade que o abriga. A rebelião torna-se assim o "canon" das atitudes literárias e também musicais, como espírito revolucionário ou das posições politícas e sociais. Rebelião e revolução imprecisas. Sem objetivo concreto, 
cósmicas. 0 homem sente-se perdido, sem limites nem contornos humanos, resigna-se por antecipação a tudo quanto lhe venha dessas realidades informes que vê crescer em torno de si, em cuja inexorabilidade acredita. Como não pode, porém, abdicar de sua natureza humana, experimenta uma íntima rebelião cuja origem e cujo objeto desconhece. Cria-se o terrível processo de auto-anulação, inicia-se a perda do sentido do real. Há uma desnaturalização da sociedade, constante, que enche de angústia seus membros, os quais apelam para um poder público transcendental que logre disciplinar os mecanismos que eles mesmos puseram em marcha, ao renunciar às suas comunidades naturais. Aspira-se, com estupidez historicamente inédita, curar o dano com mais dano, mediante a intensificação e a universalização do dano. Assim, por exemplo não existe hoje um deslinde categórico entre os funcionários públicos e os capitães de indústria. O capitão de indústria é também, em razão de sua função, funcionário do Estado. A comissão suprema da planificação é simultânea e inseparavelmente uma instituição política e econômica. Afirmar que os diretores constituem a classe governante, quase equivale dizer que esta é a burocracia estatal. Ambas, largamente, se confundem.

A carestia da vida proveniente da depreciação geral e continuada da moeda, dando lugar à intervenção estatal em preços e existências, a tributação excessiva, sem que em um ano se possa saber o que se deverá pagar no seguinte é a linha descendente, que terminará por levar-nos à desorganização da vida econômica e social produzida pela catástrofe monetária e os excessos fiscais. Estes aspectos precisam ser apontados com bravura e boa fé. O dever de fazê-lo conclama os juristas, mesmo que seja somente para demonstrar que o pais legal arruinou o país real. E qual o grande perigo desse encaminhamento? O grande perigo, o maior de todos é o empobrecimento e degeneração subjetiva, interior, e, o que mais se deve temer é que o homem médio não se dê conta suficiente da perda de valores humanos que a racionalização traz consigo. Atrás do otimismo progressista, na obscuridade do subconsciente, como também na consciência dos que contemplam com ceticismo a marcha ascendente do progresso, se eleva, ainda que na maioria das vezes sob forma de uma inquietude anônima, a consciência de que algo não anda bem. É uma espécie de Leviatã moderno "monstro frio e cruel" soma de entidades abstratas que delimitam cada dia mais a esfera de liberdade do homem. Aquilo que EdUARDo SPRANGER chamava degeneração consti- 
tutiva do sentido da verdade, o singular fenômeno que faz com que no âmbito da estrutura psíquica puramente política se atrofie o órgão da objetividade e da verdade.

A discussão teórica ou parlamentar sobre se vivemos um estado de direito tornou-se diálogo estéril, - pobre semântica e conceitualmente pela inocuidade de seus efeitos.

A linguagem vigente não estimula a razão jurídica nacional, pela incapacidade de criar relação lógica na comunicação, gerando contradição antidialética entre a mensagem e a realidade. É como se o processo parasse pela inércia do sentido de ação. Fomos tomados por uma espécie de êxtase político, sublimando a fantasia de um futuro promissor e abatidos pelo medo de exclamar. Exclamar qualquer coisa. Quem não estiver a favor está contra. Esta é a dramática tautologia imperante. E estar contra, nunca é considerado como o devera - um comportamento construtivo, de amor ao Brasil, de respeito às instituições e, principalmente legítimo pendor democrático, não comprometido com o totalitarismo seja ele de direita ou de esquerda.

Vivemos no plano político aquela situação que BATESoN na psicologia patológica classificou de "duplo - vínculo", estimulador de desequilíbrio esquizofrenógeno, exemplificando com a mãe possessiva que aconselha o seu filho a ser independente e, se ele atende, sofre a reação do impulso materno, se desatende, é reprimido por ser desobediente. Tal figuração transposta para o plano político gera a mesma situação com as mesmas conseqüências. Quer-se a oposição, mas, se ela realmente ocorre é contida, se não ocorre é reprimida.

Temos que o Brasil é nação no sentido histórico do termo, que se está convertendo em nação, na acepção política do vocábulo. Temos que os fatores que conduzem a essa transformação são o desenvolvimento econômico-social e a necessidade de adotar quadros institucionais que o tutelem e facilitem sua promoção. Ocorre, entretanto, que o desenvolvimento é um processo global e não apenas econômico. Somente engajando a sociedade, como um todo, nesse processo de desenvolvimento, é que se pode levá-lo adiante. E o processo mesmo, em seu automatismo social, suscita esse compromisso total da comunidade, independentemente de uma ação dirigida de propósito nesse sentido. Em tais condições, surgem, de um lado, certo repertório de possibilidades reais e ideais - as características geo-econômicas do país, seu contingente demográfico, seus padrões de cultura - e, de outro, determinadas opções político- 
-sociais. Essas opções se escalonam em complexa articulação de relações de meio a fim, apresentando-se algumas delas, contudo, como fins últimos. Se, em sentido mais profundo, o fim último de toda associação natural é a humanização do homem, o fim último que se apresenta, politicamente, a uma comunidade em processo de desenvolvimento, que assume sua personalidade histórica própria, é a afirmação de si mesma, da comunidade como nação.

O caminho para a reconstrução nacional, tarefa suprema que cabe a todos nós empreender, possivelmente encontrará suas fontes numa retomada de confiança do país em si mesmo. Para isso é preciso que se restabeleça a confiança no próprio povo brasileiro, a fim de que não se quebre a legitimação do poder. Em um autêntico regime democrático o povo deverá ter o direito de votar para mudar o sentido de suas aspirações. Se o direito de votar implica obrigação de aceitar o status quo, esse voto tenderá a assumir mais e mais a forma de um protesto.

As medidas repressivas em geral adotadas no decurso dos derradeiros anos não podem ser de duração indefinida e nem parece ser este o propósito imperante, como fazem crer as últimas manifestações governamentais. Por outro lado é evidente que a solução de tais questões não podia ter sido reservada pela constituição ao arbítrio do executivo. Logo, há de estar nos textos, por intuição ou por interpretação. Mas, se está nos textos cabe aos juristas interpretá-los. O poder da hermenêutica constitucional são os juristas.

O conjunto de condições objetivas que constitui o estado de uma comunidade nacional é sempre acompanhado por uma consciência social, onde se reflete. O que nos falta é uma tomada de consciência objetiva de nossa realidade, por parte de nossos melhores homens, especialmente os juristas, privados de visão histórica segura e global, por isso desnorteados e divididos em confusões elementares, o que contribui para o atraso de nosso processo de desenvolvimento, pois não há interpretação sem categorias prévias de interpretação. A divagação doutrinária, a mística social, o onirismo político longe de permitirem uma prefiguração útil do futuro, opõem-se precisamente à consecução do progresso. O conhecimento objetivo do dado social, a explicação minuciosa, exata, lúcida do estado da nacionalidade, são a condição para que se possa elaborar o melhor projeto possível do futuro, pela simples razão de que, quando obtemos uma idéia clara do presente, 
vemos o que nela se contém potencialmente, permitindo-nos conceber o futuro como função imediata e contínua do presente, com o que se elimina ao máximo o coeficiente de surpresa.

Enfim, essas explosões do nosso raciocíonio vivencialmente concatenado é a única homenagem que sentimos ser compatível com o espírito das arcadas. Aqui sempre se acendeu a chama do idealismo e da liberdade na ação das grandes figuras que constituem a glória desta Casa. Repetimos, para terminar, o que disse o nosso inolvidável RUY em memorável discurso proferido nesta Casa em 17 de dezembro de 1909, ainda com absoluta oportunidade: "Não há nada mais relevante na vida social, que a formação do sentimento de justiça; e este resultado é, na sua maior parte, uma função da cultura jurídica, distribuída nos grandes estabelecimentos de ensino superior. Cedendo, provavelmente, à intuição de que nela reside o eixo de toda a civilização cristã... consagrou ao direito duas faculdades, uma ao norte, outra ao sul, como situações polares dominantes no movimento de nosso mundo moral. Sem desfazer, porém, na realeza de Olinda, a pérola do Norte, amortecida talvez, mas, não desluzida jamais do seu oriente, não se poderia seriamente duvidar que o magistério de São Paulo exerceu sempre de um grau mais alto, com influência muito mais poderosa e muito mais larga amplitude, a sua missão nacional. Bolonha famosa outrora, entre as cidades letradas pela sua "universitas scholarium", pelos "doctores legentes", se chamava por antonomásia, a um tempo, "a douta e a livre", associando, nas suas antigas moedas, à legenda solene de seus direitos, "Libertas" o foro por excelência de mestra: "Bononia docet". À academia de São Paulo, indisputavelmente, lhe cabem os dois títulos no mesmo brasão: "Professa a liberdade, e ensina a justiça". 